\title{
Scholarship and Sports Diplomacy: the Cases of Japan and the United Kingdom
}

\author{
J. Simon Rofe | ORCID: 0000-0001-9423-6644 \\ Centre for International Studies and Diplomacy, SOAS University of London, UK \\ jsimon.rofe@soas.ac.uk
}

Verity Postlethwaite | ORCID: 0000-0003-3246-4611

Japan Research Centre, SOAS University of London, UK

vpı@soas.ac.uk

\begin{abstract}
This article explores scholarship regarding diplomatic processes and actors engaged in recent international sport events hosted by the United Kingdom and Japan. The article points to the range of actors involved, focusing on organizing committees, and assesses the effectiveness of sports diplomacy at a range of levels that go beyond a focus on the state. It uses international sport events documentation, global media archives, and public and private comments related to the United Kingdom and Japan. The article addresses three key issues: 1) Olympic-dominant discourse: the dominance and shift in process between hosting an Olympic Games and onto other events; 2) Westerndominant discourse: the differences between Japan and the UK in demonstrating distinct "East" and "West" sports diplomacy approaches; 3) State-dominant discourse: the role of knowledge exchange and elite networks that transcend the state and involve a range of different actors, such as the organizing committee.
\end{abstract}

\section{Keywords}

sports diplomacy - international sport events - sport mega-events - non-state actors diplomatic processes - global sport - United Kingdom - Japan 


\section{Introduction}

Sport, and in particular, hosting international sport events forms a key dimension to diplomatic relations between nation-states, non-state actors, and individuals. The historical context to international sport events ${ }^{1}$ transcends a complicated legacy of political tensions, cultural exchanges, and economic development. Complicated further as these legacies can be traced across several different eras spanning nineteenth-century western imperialism, the global conflicts of the twentieth century, the spread of neoliberal capitalism in the post-World War II era through to the twenty-first century. Scholars from a variety of academic disciplines have contributed to a burgeoning discourse on sport and diplomacy globally through the study of history, ${ }^{2}$ sociology, ${ }^{3}$ diplomacy, ${ }^{4}$ political science, and international relations. ${ }^{5}$

Sports diplomacy is a term that has gained increasing prominence among practitioners and scholars. Sports diplomacy is the lens to view the network of evolving networks within the realms of sport and diplomacy. It offers, under the premise of the three core characteristics of diplomacy - representation, negotiation, and communication - a conceptual understanding of sport that 1) provides the navigation skills for practitioners to connect with and learn from different parts of the sports diplomacy ecosystem; and 2) helps provide critical reflection for policymakers and practitioners, and scholars, to enhance their practice in these overlapping and conjoined spaces. ${ }^{6}$ The evolving nature of the discourse on sports diplomacy makes it a dynamic field to address with future evolution integral to its own conception.

1 The authors use the phrase international sport event to capture a range of events, including sport mega-events, single or multi-sport events, and regional, emerging or second order events. For further discussion on the classification of events beyond sport mega-events see: Black, D. "Dreaming Big: The Pursuit of 'Second Order' Games as a Strategic Response to Globalization." Sport in Society, 11 (4) (2008), 467-80. For further discussion on the classification of megaevents see also Müller, M. "What Makes an Event a Mega-event? Definitions and Sizes." Leisure Studies 34 (6) (2015), 627-42.

2 Keys, B. "Political Protection: The International Olympic Committee's UN Diplomacy in the 198os." International Journal of the History of Sport 34 (11) (2016), 1161-78.

3 Ho, G. "Olympic Culture Shock: When Equestrianism Galloped to Hong Kong." Asia Pacific Journal of Sport and Social Science 1(1) (2012), 22-36.

4 Murray, S. Sports Diplomacy: Origins, Theory and Practice (London: Routledge, 2018).

5 Yamamoto, M. "Development of the Sporting Nation: Sport as a Strategic Area of National Policy in Japan." International Journal of Sport Policy and Politics 4 (2) (2012), 277-96.

6 Rofe, J.S., ed. Sport and Diplomacy: Games Within Games (Manchester: Manchester University Press, 2018). 
This article considers the often an overlapping, complimentary but sometimes tension-filled relationships between actors involved in the bidding for, and the designing and organizing of an international sport event. State actors, including national and local governments, are often central to explorations and the empirical focus of international sport event studies. This focus makes sense when one considers the economic, political, and social inputs and outcomes surrounding an event for the hosting nation-state. As the events themselves have grown in size and scope they have garnered growing academic attention and consequent growth in sophistication and analysis. In one sense, the developments represent a wider body of actors considered such as organizing committees, international sporting federations, sponsors, media channels, and associated business communities. This growth is also represented by the variety of concepts and disciplines attempting to understand processes and relationships involved in international sport events, such as soft power, public diplomacy, stakeholder management, and nation branding. This article acknowledges both the complex and temporally transient groupings which form to host such events, alongside the multitude of different approaches and concepts that seek to consider explain such phenomena.

This article uses international sport events documentation, global media archives, and public and private comments from actors related to the United Kingdom (UK) and Japan. This focus results from the circumstance of the UK having hosted the Olympic and Paralympic Games in 2012, then the Rugby World Cup in 2015, while Japan hosted the Rugby World Cup in 2019 and hosted the Summer Olympic and Paralympic Games in 2021. The timeliness of the endeavor could not be more relevant so as to complement the UK and Japan connection; there notably have been several other events in the East Asian region, such as the 2018 Winter Olympics in PyeongChang, South Korea. ${ }^{7}$ Evidence collected from documents, global media accounts, and individuals connected to UK and Japan endeavors raises debate around broader diplomatic practices: particularly knowledge exchange and diplomacy in the context of Olympic and non-Olympic international sport events.

The discourse highlights the range of actors, including organizing committees in diplomatic processes, and assesses the effectiveness of sports diplomacy at a range of levels that go beyond a focus on the state. By exploring the diplomatic processes and actors in Japan and UK hosted international sport events, this article will complicate the dominant voices and the ways in which

7 Woo Lee, J. "Sport Diplomacy at the 2018 Winter Olympics in PyeongChang: the Relations between North and South Korea." In Handbook of Sport in Asia, eds. F. Hong and Z. Lu (Abingdon: Routledge, 2021), 227-37. 
individuals, state, and non-state actors function, revealing nuances in ways that sport transcends national sovereignties - at both sub-state and supra-state levels. The three key issues raised here are: 1) Olympic-dominant discourse: the dominance and shift in process between hosting an Olympic Games and onto other events, such as the Paralympic Games and the Rugby World Cup; 2) Western-dominant discourse: the differences between Japan and the UK in demonstrating distinct "East" and "West" sports diplomacy approaches; 3) state-dominant discourse: the role of knowledge exchange and elite networks that transcend the state and involve a range of different actors, such as the organizing committee and manifest in other dimensions such as human capital/labor market both of which act as a venue for knowledge exchange as a mode of soft power. The exemplars of Japan and the UK explored here pose questions of sport and diplomacy specifically, and also offer avenues for further research to others to explore how this could be translated through other lenses such as cultural forms and other international events e.g., world leader summits, activist group marches, and interest group congresses and conferences.

\section{The UK and Japan Hosting Contexts}

The historical developments of global sport and international sport events have gone hand in hand, and it should be no surprise that they have garnered increasing levels of academic interest. In particular around the largest sport mega-event, the Olympic Games. ${ }^{8}$ Two prominent research debates have been: firstly, why nation-states invest in hosting international sport events given the cultural, political, and economic risks. Secondly, what role international sport events play in relation to nation-states and international relations more broadly. An allure of the research is to analyze the challenges and opportunities of the quadrennial shift in the geographic and spatial focus of the hosts of the Summer Olympic and Paralympic Games. A significant literature has arisen here: Kelly and Brownell, for example, collated chapters around the concepts of national, regionalism, and globalism in the context of the Olympic movement and East Asia. ${ }^{9}$ The authors demonstrate that as regards the Western concept of international sport events - legacy - hosting is not transferrable wholesale to East Asian contexts. Moreover, the differentiations between East

8 Whannel, G., and J. Horne. Understanding the Olympics (London: Routledge, 2016).

9 Kelly, W.W., and S. Brownell. The Olympics in East Asia: Nationalism, Regionalism, and Globalism on the Center Stage of World Sports. Council on East Asian Studies at Yale University. Yale CEAS Occasional Publications, Volume 3 (New Haven: Yale University, 2011). 
Asian nation-states that have hosted and co-hosted international sport events, including China, South Korea, and Japan, cannot be homogenously discussed through Western-influenced ideas of sport management, event legacies, nor in this essay's case, sports diplomacy.

In the context of Japan and sport, Sakaue and Thompson argue the Olympic Movement and hosting the event has had "an inordinate significance to and influence on Japan."10 The focus of literature is often on the historical aspects of Japan's connections, especially in relation to the American and British influence on modern Japanese sporting cultures, such as the adoption of baseball or rugby. The role of international sport events and especially that of the Olympics, serves as a display of Western sport and connection to other nations by way of inciting national pride. This role and attraction to Japan can be demonstrated by their track record in bidding (six unsuccessful bids) and hosting the Winter and Summer Olympic Games (1964, Tokyo Summer; 1972, Sapporo Winter; 1998, Nagano Winter; and 2021, Tokyo Summer). Further to this, Japan has a history with the Paralympic Games and Paralympic Movement as it hosted equivalent games in 1964 Tokyo Summer; 1998 Nagano Winter; and 2021, Tokyo Summer.1 ${ }^{11}$ The attraction of hosting international sport events for Japan has domestic and international features, however there is a significant foreign policy and international relations pull to why Japan invests and engages so much with international sport events.

Japan's approach to hosting international sporting events has drawn the focus of scholars looking at the period after the Second World War. During this period, Japan and Allied Occupation Authorities used sports as a tool to enhance its national image and diplomatic agenda, including its return to the IOC and other international sport governing bodies. A series of diplomatic tools were utilized to demonstrate Japan's rehabilitation, such as friendship and coaching tours, where media and political actors projected narratives of reconciliation, civilized and peace between Japan and other Western counterparts. ${ }^{12}$ Focusing on the 1964 Tokyo Olympics, Abel argues the success of hosting the Games through diplomatic processes, such as the promotion of international connections allowed Japan to "build-up" soft power and "develop

10 Sakaue, Y., and L. Thompson. "The Rise of Modern Sport and the Olympic Movement in Japan." In Handbook of Sport in Asia, eds. F. Hong and Z. Lu (Abingdon: Routledge, 2021), $135-48$.

11 Ogura, K. "Visions on the Legacy of the Tokyo 2020 Paralympic Games." In The Palgrave Handbook of Paralympic Studies, eds. I. Brittain and A. Beacom (Palgrave Macmillan: London, 2018), 579-6o1.

12 Guthrie-Shimizu, S. "Japan's Sports Diplomacy in the Early Post-Second World War Years." International Area Studies Review 16 (3) (2013), 325-35. 
greater knowledge and understanding of Japan."13 The focus of the literature here is in agreement about the explicit and operational way the Japanese state has harnessed sport to enhance its domestic cohesion and international standing. The evidence is engaged with traditional notions of diplomacy, debates about soft power and public diplomacy, and the focus on state to state interactions. Less attention has been paid to non-Olympic international sport events hosted by Japan ${ }^{14}$ and, also, non-state actors involvement in Japan's use of sports diplomacy processes. These two aspects are explored here, in particular the use of rugby union and a broader understanding of diplomatic processes and actors in Japan's sports diplomacy.

Turning to the context of the UK, similarly to Japan, it has a significant connection to engaging with the Olympic Movement and hosting Olympic Games. London became the first city to host the modern Summer Olympic Games three times in 2012, following on from 1908 and 1948. A range of interdisciplinary scholars have drawn upon the London 2012 Olympic and Paralympic Games to consider aspects of soft power strategies, ${ }^{15}$ city diplomacy, ${ }^{16}$ public diplomacy, ${ }^{17}$ and cultural diplomacy. ${ }^{18}$ The blend of these different approaches and the actors cited within these literatures references media outlets, UK Government departments, the Mayor of London, international sporting federations, the organizing committee, and various community groups. In identifying a particular tranche of high-profile global sports clubs, mainly within Association Football, Rofe explains, "Both football and diplomacy in the twenty-first century are a 'squad game."'19 Particularly, in exploring the role of Manchester

13 Abel, R.J. "Japan's Sporting Diplomacy: The 1964 Tokyo Olympiad." International History Review 34 (2) (2012), 203-20, at 203.

14 A notable exception is the Fédération Internationale de Football Association co-hosted in 2002 by Japan and South Korea, given the complexity of co-hosting this is not considered substantively in this paper. For a comprehensive overview see: Horne, J., and W. Manzenreiter, eds. Japan, Korea and the 2002 World Cup (Abingdon: Routledge, 2013).

15 Grix, J., and P.M. Brannagan. 'Of Mechanisms and Myths: Conceptualising States 'Soft Power' Strategies through Sports Mega-events." Diplomacy and Statecraft 27 (2) 2016, 251-72; Grix, J., and D. Lee. "Soft Power, Sports Mega-events and Emerging States: The Lure of the Politics of Attraction." Global Society 27 (4) (2013), 521-36.

16 Acuto, M. "World Politics by Other Means? London, City Diplomacy and the Olympics." Hague Journal of Diplomacy 8 (3-4) (2013), 287-311.

17 Pope, M.R.G. "Public Diplomacy, International News Media and London 2012: Cosmopolitanism тм." Sport in Society 17 (9) (2014), 1119-35; Pamment, J. British Public Diplomacy and Soft Power. (Basingstoke: Palgrave Macmillan, 2016).

18 Bourgeois, T. "London 2012 Olympics: Exercises in Cultural Diplomacy." Place Branding and Public Diplomacy 15 (3) (2019), 198-205.

19 Rofe J.S. "It is a Squad Game: Manchester United as a Diplomatic Non-state Actor in International Affairs." Sport in Society: Cultures, Commerce, Media, Politics 17 (9) (2014), $1136-54$. 
United Football Club "as a non-state actor in contemporary diplomatic international affairs," Rofe notes that while "[t]here are still actors who have primacy: nation states and star strikers," both football clubs or nation-states "must pay increasing attention to others such as up and coming members of the 'squad,' the global media, publics, and commercial interests" who constitute a range of different actors in contemporary diplomacy. Nonetheless, across the broader literature and the practice of sports diplomacy, the centerpiece is the nation-state and UK government and official modes of diplomacy connected to the Olympic Games and the IOc. Diplomatic leverage is framed at the state level and does not reach beyond into other realms, such as the Paralympic Games, the media, local communities, or individual athletes. A notable exception is the scholarship of Beacom who conceptualizes the distinct mode of "Paralympic Diplomacy" from the inception of the Stoke Mandeville Games in 1948 through to the recent London, Sochi, and Rio de Janeiro Games. ${ }^{20}$ The fabled visits of Pierre de Coubertin to the United Kingdom in the 188os, the influence of the values extolled in Tom Brown's School Days (1857) as the inspiration on the Modern Olympic movement, speak to the shaping influence of the United Kingdom. Allied to a rich and extensive experience of hosting international sport events the UK has an established sporting brand.

Further to the UK connection to the Olympic and Paralympic Movements, it also has a lengthy history and connection to other international sporting events and movements. Polley and others speak of a British sports diplomacy ${ }^{21}$ which connects the UK with a particular philosophy of sport, a history professionalization and commercialization of sport and the legacies of empire and sport. The relevance for this article is the connection between the UK and sports with a particular Commonwealth heritage, such as cricket, netball, and rugby union. There has been considerable research on cricket and rugby union, and a growth of research on netball, but very few examples used examples where non-Commonwealth nations host or engage with these sports. It is here that this paper makes a unique contribution, as it brings together the focus of a traditional sport in Rugby Union with Japan as a host nation of sports premier's competition, the Rugby World Cup, outside of its traditional heartlands. What this demonstrates is the value of embracing an expanded

20 Beacom, A. International Diplomacy and the Olympic Movement (London: Palgrave Macmillan, 2012), 235-56.

21 Polley, M. "The Amateur Ideal and British Sports Diplomacy, 1900-1945." Sport in History 26 (3) (2006), 450-67; Collins, T. Sport in Capitalist Society: A Short History. (London: Routledge, 2013); Kidambi, P. "Sport and the Imperial Bond: The 1911 'All-India' Cricket Tour of Great Britain." Hague Journal of Diplomacy 8 (3-4) (2013), 261-85. 
understanding of the overlapping realms of sport and diplomacy. In turn, moving beyond a focus on a particular nation-state, a single event or sport, allows for a nuanced understanding of the complexities and interconnections of the networks of sports diplomacy which include, but are not limited to the nation-state and take into account the sub-state and supra-national dimensions of international sport events.

\section{Global Diplomacy and Sport}

As an explanatory tool, this article draws upon the global diplomacy analytical framework in recognizing the transactional and multi-directional concepts of communication, representation, and negotiation that underpin diplomatic practice. The framework consciously looks beyond spatial antecedents that often characterize diplomacy in western, state centric modalities. Instead, the global diplomacy framework considers alternative perspectives as the basis of diplomatic practice. It moves beyond traditional understandings of diplomacy as the preserve of nation-states; of foreign ministries; of men, and instead look to consider diplomacy as practiced by a range of actors across a range of transactions and networks. The framework sees diplomacy resting upon those essential characteristics as communication, representation, and negotiation: dimensions which preceding scholars of diplomacy have engaged with. In this light, the framework accommodates heterarchical approaches to power such as the Mandala. The Mandala, with South Asia origins, reflects an approach to power which stresses networks of connectivity radiating out in concentric circles from a central point - which forms a "wheel of power."22 A vital feature of this approach is that players, or actors, identities may shift in relation to others; and this can be seen in the spread of Mandala thinking across Asia and to the Han Dynasty in China. In this light, it contributes to a 200o-year old antecedent to our focus on international sport events in East Asia. The key dimension of the global diplomacy framework in this regard is the relational and non-hierarchical approach to diplomacy. As such, our work consciously embraces approaches that go beyond the western canon.

Furthermore, our approach eschews a binary understanding of state and non-state actors and their diplomatic capabilities. Instead, we recognize that both states and non-state actors are not monolithic polities solely defined by one identity, and that a range of polities can practice diplomacy. Former UK

22 Holmes, A., with J.S. Rofe. Global Diplomacy: Theories, Types, and Models (Boulder: Westview Press, 2016), 141. 
diplomat, Shaun Riordan, has warned against new modes of diplomacy. He argues "they are frequently conceptually confused, risk new kinds of diplomacy being seen as an end in themselves, rather than as part of broader diplomatic strategies, and, more seriously, risk emptying the concept 'Diplomacy' of any meaning." ${ }^{23}$ His critique of modes of diplomacy includes food diplomacy, dance diplomacy, and most relevant for our study, sports diplomacy. Our conception of sports diplomacy is distinguishable from this critique because it places sports diplomacy within the multi-faceted and multi-directional global diplomacy framework. ${ }^{24}$ In doing so the work acknowledges the antecedents in Hocking's multi-stakeholder diplomacy, and Wiseman's polylateralism. ${ }^{25}$ Wiseman identified polylateralism at the turn of the twenty-first century as the relationship between official entities, centered on the nation-state "and at least one unofficial, non-state entity" which adopted similar reciprocal behaviors. Wiseman developed polylateralism in describing it as "Diplomacy's Third Dimension" as a means of explaining state to non-state, and non-state to state diplomacy. ${ }^{26}$ In other words, our conception of sports diplomacy is not in addition to but embedded in longstanding diplomatic practices.

Within the sports diplomacy discourse there has been an absence of focus on actors beyond the state level, such as the organizing committees of international sport events and this has in turn shaped and impacted the methodologies that have been employed. The organizing committee is the fulcrum of decision making and knowledge exchange in an international sport event. Equally, the organizing committee in its most reductive form is dedicated purely to delivering a time constrained global sporting spectacle. Lord Sebastian Coe's appointment as Chairman of the London Organising Committee of the Olympic Games (LOCOG) from 2004 until the conclusion of the Games in 2012 is notable given his profile as a former double Olympic Champion, British Member of Parliament, and peer of the realm who helped secure the Games in 2005. Their resonance among the domestic populace and the wider Olympic Community,

23 Riordan, S. “Gastronomic Diplomacy Without Strategy Is ... Lunch," 2 July 2017 http://www. shaunriordan.com/?p=505 accessed 24 October 2017.

24 Rofe, J.S. "Sport and Diplomacy: A Global Diplomacy Framework." Diplomacy and Statecraft 27 (2) (2016), 212-30.

25 Wiseman, G. "Polylateralism' and New Modes of Global Dialogue," Discussion Paper No. 59, Leicester Diplomatic Studies Programme, 1999. Republished as 'Polylateralism' and New Modes of Global Dialogue." In Diplomacy, Volume III, eds. C. Jönsson and R. Langhorne (London: SAGE, 2004); Hocking, B. "Multistakeholder Diplomacy: Forms, Functions, and Frustrations." In Multistakeholder Diplomacy: Challenges and Opportunities, eds. J. Kurbalija and V. Katrandjiev (Malta: DiploFoundation, 2006).

26 Wiseman, G. “Polylateralism': Diplomacy's Third Dimension." Public Diplomacy Magazine 1 (2010), 24-39. 
came through in the conclusion of his "Made in Britain" remarks to close the Paralympic Games (9 September 2012). Through a number of recent academic studies into the patterns of sport mega-event organizing committees ${ }^{27}$ and wider interrogations of the impact and legacy of international sport events, ${ }^{28}$ the organizing committee has been gaining greater prominence. A number of high-quality studies have been undertaken around "stakeholder relationships," or "impacts and evaluations," or "strategy and planning." ${ }^{29}$ Conceptually, this article enhances management-centered perspectives, and augments the nation foci with the broader conception provided by the global diplomacy framework in recognizing that the organizing committee has become a central actor in diplomatic discourses of international sport events. As such, the organizing committee is a means of understanding supra- and sub-state actors that contribute to understanding contemporary international sport events.

The scope of sports diplomacy has hitherto had limited focus on the role the non-state actor plays in the contemporary international sport events landscape. Keys has explored the roles of non-state actors, particularly, of the International Olympic Committee (IOC), the United Nations (UN), and Human Rights Watch (HRW) during the Cold War and in the 199os' bid from Beijing to host the Summer Olympics. ${ }^{30}$ Keys shows through her archival research the influence of individuals, organizations, and movements on international sport events. Keys' work focuses on the effect of particular agendas on these international sport events. However, this piece also raises the important methodological in looking at these events, namely the issue of access to sources and individuals who are willing to disclose information about internal decision-making. As Keys notes "HRW archives dealing with internal decision-making are almost entirely closed to researchers." ${ }^{31}$ Scholars' efforts to access internal documents and insight are hampered by the inability to access archival sources and key protagonists due to organizational embargoes on documents and non-disclosure agreements between staff, representatives, and athletes that engage with international sport events. ${ }^{32}$ Consequently, the

27 Parent, M. "Evolution and Issue Patterns for Major-sport-event Organizing Committees and Their Stakeholders." Journal of Sport Management 22 (2) (2008), 135-64.

28 Tomlinson, A., ed. The Olympic Legacy: Social Scientific Explorations (London: Routledge, 2017).

29 Heere, B., K. Kim, M. Yoshida, H. Nakamura, T. Ogura, and S.Y. Lim. "The Impact of World Cup 2002 on the Bilateral Relationship between South Korea and Japan." Journal of Sport Management, 26 (2) (2012), 127-42.

30 Keys, B. "Harnessing Human Rights to the Olympic Games: Human Rights Watch and the 1993 'Stop Beijing' Campaign.” Journal of Contemporary History, 53 (2) (2018), 415-38.

$31 \quad$ Ibid., 418.

32 Nichols, G., and R. Ralston. "The Legacy Costs of Delivering the 2012 Olympic and Paralympic Games through Regulatory Capitalism." Leisure Studies 34 (4) (2015), 389-404. 
research around contemporary international sport events are largely based on private interviews, publicly accessible documents, and media reports.

The global diplomacy analytical framework alleviates the limitation to a notable extent. The approach allows for a greater scope in recognizing that there are a range of actors engaged in framing knowledge exchange within international sporting events. These include the organizing committee, which itself has an evolving and self-referencing remit. In other words, a range of non-state actors are vitally important to understanding international sport events, premised on the view that there are manifold actors involved in the transactions of diplomacy occasioned by sport. This view is supported by the broader academic debate around this rise of international sporting governance and autonomy of sporting entities. Allison and Tomlinson advocate using the term "sporting international non-governmental organizations" (SINGOs) to understand the rise (and demise) of dominant organizations, such as, the IOC; and the system of their interactions. ${ }^{33}$ The complex landscape of nonstate sporting actors poses challenges to what, who and how international sport events are influenced within and beyond the nation-state. Sporting non-state actors provide not only challenges for international sport events organizing committees, but also opportunities. As such, the relationship is multi-directional.

Twin elements have dominated the diplomacy of non-state actors concerning sport. One has been the study of the Olympics Movement, and the other a focus on the individual, with the sportsman or sportswoman, coaches, and administrators cast as diplomats. Morgan considers the diplomatic role tennis player Arthur Ashe played in confronting racial apartheid South Africa in the early-1970s. ${ }^{34}$ The part of Ashe is accounted as both a "real and imagined" transnational actor in public and private political debate over apartheid. Equally, Rofe and Tomlinson explore the role played by FIFA Secretary General, Sir Stanley Rous, as a de facto ambassador on behalf of FIFA for the UK government with respect to Democratic People's Republic of Korea's participation in the 1966 men's World Cup at a time when the North Korean state was not recognized by the United Kingdom. ${ }^{35}$ The role of international sport events and non-state actors in changing public and private perceptions is present in

33 Allison, L., and A. Tomlinson. Understanding International Sport Organisations: Principles, Power and Possibilities (London: Routledge, 2017).

34 Morgan, E.J. "Black and White at Center Court: Arthur Ashe and the Confrontation of Apartheid in South Africa." Diplomatic History, 36 (5) (2012), 815-41.

35 Rofe, J.S., and A. Tomlinson. "The Untold Story of FIFA's Diplomacy and the 1966 World Cup: North Korea, Africa and Sir Stanley Rous." International History Review 42 (3) (2020), 505-25. 
the study and methodology of sporting activities; for example, Beacom and Brittain consider the diplomatic role of the more youthful Paralympic movement, ${ }^{36}$ and Baker et al. regarding the role non-state actors in the sport for development and peace agenda. ${ }^{37}$ These essays demonstrate the dynamics of individuals, movements and agendas in the diplomatic angle of international sport events and movements.

Beyond interpreting non-state actors as individuals and organizations, narratives are shaped, mythologized, and challenged by the perceptions created by various forms of media and commentary. Larson and Park consider the role of global television and the politics of the Seoul Games in their examination of that international sport events on South Korea and its democracy towards the end of the Cold War. ${ }^{38}$ They argue that the Games performed a crucial communicative role as a "burgeoning Olympic spectacle." 39 As has been noted, the allure of the scale and the theater of a sport mega-event, in particular, the Olympics and Paralympics, have received a good deal of scholarship. The research focuses on how the event contributes to and sometimes mirrors concurrent state-based international relations. ${ }^{40}$ This brings together the notion of mimicry that McConnell and Dittmer recognize in their work, and the "theater of diplomacy" that Shimazu does in her work. ${ }^{41}$ Larson and Park take another dimension by looking at the development and use of global television among distinct populations in understanding diplomatic transactions during the Seoul Summer Games. In each respect the centrality of the state-to-state relations challenges the understanding of international sport events and opens a debate as to the role of non-state actors and entities.

36 Beacom, A., and I. Brittain. "Public Diplomacy and the International Paralympic Committee: Reconciling the Roles of Disability Advocate and Sports Regulator." Diplomacy and Statecraft 27 (2) (2016), 273-94.

37 Baker, R.E., P.H. Baker, C. Atwater, and H. Andrews. "Sport for Development and Peace: a Program Evaluation of a Sport Diplomacy Initiative." International Journal of Sport Management and Marketing 16 (1-2) (2016), 52-70.

38 Larson, J.F., and H. Park. Global Television and the Politics of the Seoul Olympics (Boulder: Westview Press, 1993).

39 Ibid., 141.

40 Redeker, R. "Sport as an Opiate of International Relations: The Myth and Illusion of Sport as a Tool of Foreign Diplomacy." Sport in Society 11 (4) (2008), 494-500.

41 McConnell, F., T. Moreau, and J. Dittmer. "Mimicking State Diplomacy: The Legitimising Strategies of Unofficial Diplomacies." Geoforum 43 (2012), 804-14; Shimazu, N. "Diplomacy As Theatre: Staging the Bandung Conference of 1955." Modern Asian Studies 48 (1) (2014), $225-52$. 


\section{Diplomatic Processes: Multi-Sport versus Single Sport}

Our first empirical exploration focuses upon the differences between the larger dominant multi-sport federations (such as the IOC), and single sports federations (such as World Rugby). In this context, although not as prevalent as the IOC, World Rugby (formerly the International Rugby Board 1886-2014) is a significant global sports federation which has rich origins in the colonial era of the British Empire in the 19th century. In the contemporary period, it has 100 full members and 18 associates, and the pinnacle of its calendar is the four-yearly Rugby World Cup. The dominant focus of diplomatic scholarship around the Rugby and the Rugby World Cup is the 1995 event in South Africa, not least because of the iconic image of President Nelson Mandela wearing a Springbok jersey to award the Webb Ellis Trophy to the winning South African captain Francois Pienaar. ${ }^{42}$ The 2019 Rugby World Cup in Japan represented the first Asian nation-state to host the competition, and the first the tournament was held outside of a traditional rugby-playing nation. Therefore, this particular international sport event represents an opportunity to explore not only the Rugby World Cup in Japan, but also consider the shifting narrative in scholarship and beyond the traditional host nations in the rugby world.

In contrast to World Rugby with its single sport focus, the IOC - is recognized as the pre-eminent dominant of singos. ${ }^{43} \mathrm{~A}$ large area of recent investment by the IOC and International Paralympic Committee (IPC) has been around knowledge transfer and professionalization between organizing committees. Part of this is to offer insights into other iterations of the Games, but also, to reduce the costs associated with hosting the events which saw the number of bidding nations reduced to one for the summer 2024 and 2028 Games. The IOC has facilitated knowledge exchange in running an official Observer Program since Vancouver 2010 and is part of the more comprehensive "Olympic Games Knowledge Management" program. ${ }^{44}$ The IOC claims the program to be useful to "witness how things are done, but also study specific areas so that they can learn and improve upon those subjects within their own organizational and cultural context." 45 The growth of formal knowledge transfer is a pertinent area

42 Carlin, J. Invictus: Playing the Enemy: Nelson Mandela and the Game that Made a Nation. (London: Atlantic Books, 2008).

43 Allison, L., and A. Tomlinson. Understanding International Sport Organisations.

44 Learning from the Past: Getting Ready for the Future, IOC, 25 October 2011, https://www. olympic.org/news/learning-from-the-past-getting-ready-for-the-future (accessed 14 June 2019).

45 "IOc Observer Programme Provides 'Behind the Scenes' Experience for Future Games Organisers' Chinese Olympic Committee," 24 February 2014. http://en.olympic.cn/news/ olympic_news/2014-02-21/2309789.html (accessed 10 June 2019). 
to explore, for example, Park and Ok considered the role of the IPC Excellence Program in conjunction with the political intentions of the PyeongChang 2018 Winter Olympics and Paralympics. The authors see an opportunity for the program and experiences from other countries "can challenge existing prejudices and create new paradigms for sport for the disabled." 46 The range of activities that are connected to the IPC Excellence Program facilitates practical and theoretical knowledge transfer and were in place for the Tokyo 2021 Games and Beijing 2022 Games. This kind of formal knowledge exchange forum highlights the understanding from international federations that in order to drive their particular agendas, such as the IPC's vision for challenging discourse around sport the disabled, the organizing committees are fertile fora to shape and influence. UK-Japan relations are framed similarly in relation to the nexus in global affairs of sporting and diplomatic realms. It is here that overlapping practices and approaches allow for networks of multi-directional relationships across social, political, and economic dimensions to be seen among a broad range of actors.

The most prominent feature of sports diplomacy activity has been between the organizing committee structures of the England Rugby World Cup 2015 and the London Olympic and Paralympic Games 2012, and the Japan Rugby World Cup 2018 and Tokyo the Olympic and Paralympic Games 2021. Publicly there have been a significant number of talks, visits, and symposia between the organizers demonstrating the key practices of communication, representation, and negotiation. Tetsuya Kimura the Director-General, Japan Sports Agency stated:

Sport is an influential instrument to promoting peace, understanding and inter-cultural dialogue... I strongly believe that the outcome of this symposium will impact on the process toward 2019, 2020 and beyond. It is also my sincere hope that this symposium will be the kind of platform to exchange opinions with experts in different fields. ${ }^{47}$

The symposium was co-funded by the Japan Sport Council London, Japan Research Centre at soAs, University of London, and the Tokyo organizing

46 Park, K., and G. Ok. "2018 PyeongChang Paralympic Games and the South Korean Political Intention." In The Palgrave Handbook of Paralympic Studies, eds. I. Brittain and A. Beacom. (London: Palgrave Macmillan, 2018), 555-77, at 574.

47 "Sport and Diplomacy: Past Reflections and Looking Toward 2020," Japan Research Centre 15 May 2017, https://www.soas.ac.uk/jrc/events/15may2017-sport-and-diplomacy-pastreflections-and-looking-toward-2020.html (accessed 10 June 2018). 
committee Sport for Tomorrow program, and in doing so demonstrated the practice of sports diplomacy with a range of non-state actors engaged in knowledge exchange. This initial event acted as a catalyst: with the Sport for Tomorrow program convening a consortium of Japanese organizations from the private sector, non-governmental organizations, universities, and local and national governments. Beyond symposiums in the UK, the Sport for Tomorrow program reports and website illustrate almost a hundred and fifty different ways the program has communicated with an even greater range of stakeholders. For example, the program has promoted the Paralympic Movement in the Japan-China Exchange Focus month. ${ }^{48}$ The dialogic element of this program, inherent to diplomatic practice, showcases the global aims underpinning the breadth of opportunities for international sport events such as the Tokyo 2021 Games.

In some contrast the Japan 2019 Rugby World Cup had a more distinct focus. Rather than addressing a universalist potential, its aims were

to use the Rugby World Cup 2019 to convert the rugby potential within Japan and Asia. It is an ambitious strategy to promote growth and strengthen the game in collaboration with Asian national rugby unions and Asia Rugby. ${ }^{49}$

Asia in this instance includes a broad understanding of the geographic region, to include, India, Pakistan, Bangladesh, China, and the United Arab Emirates. As noted by the World Rugby 2017 Impact Beyond report, there are 63 scheduled projects to take place across 22 member Unions. ${ }^{50}$ The projects range from increasing participation to infrastructure development to getting rugby onto school Physical Education curricula. World Rugby, Asia Rugby, Japan Rugby, Japan International Cooperation Agency, Japan-East Asia Network of Exchange for Students and Youth, and the Sport for Tomorrow program, have collectively funded these initiatives. Here again, sports diplomacy is played out as the practice of communication is facilitated more so through the international sporting federation - World Rugby, which is representing the sport and its constituent members in the shape of national unions - and negotiating with its stakeholders to advance the organizations' overall aims. As such we see two distinct approaches: one in the case of the Rugby World Cup which

\footnotetext{
48 https://www.sport4tomorrow.jp/report/ (accessed 12 August 2018).

492019 Rugby World Cup Archive https://www.rugbyworldcup.com/2019 (accessed 28 February 2021).

$50 \quad$ World Rugby. Grow the Game. Impact Beyond 2019 (Dublin: World Rugby House, 2017).
} 
actively shapes the organizational dimension, while the Tokyo 2021 organizing committee as a time-bound project whose management group negotiates a space between the international federations, the IOC, and city and national governments.

The differences between World Rugby and Olympic and Paralympic events can be instrumentally attributed to the size and scope of funding, reach, and participation. In turn these shape the capacity for knowledge exchange between organizing committees. World Rugby is vocal about the opportunity. For example, Murray Barnett, the Head of Commercial, Marketing and Broadcast at World Rugby in 2016, at a meeting co-sponsored by the British Chamber of Commerce in Japan and the Australian and New Zealand Chamber of Commerce in Japan, emphasized both the importance of knowledge-sharing between former and future host countries while also stressing the importance of finding local solutions. Moreover, Barnett suggested changes between succeeding tournaments have different aims for the international federation:

With England 2015 set to be a record financial and participation driver and Japan 2019 a game-changer in terms of unlocking an Asian market that is home to 6o per cent of the world's youth and has experienced a 33 per cent increase in rugby participation in the last four years, World Rugby is currently undertaking a major review of the 2023 hosting model to drive further benefit to the host union, the host nation and the global game. ${ }^{51}$

Knowledge transfer for the Rugby World Cup is an internal matter coordinated by the international sporting federation itself because, as Barnett noted, the Rugby World Cup "is a private event and not funded by the government or the taxpayer." 52 The spectacle therefore, while based in Japan, was in many ways shaped by the traditional Western-led voices of World Rugby.

In contrast, the Tokyo 2021 Games and its organizing committee operate differently. Lord Deighton noted in 2015 in Tokyo, "remember, you don't have to reinvent the wheel. You already have everything you need as a template from previous Games. You just need to add a Tokyo flavour."53 Those associated with

51 British Chamber of Commerce in Japan. 2016. "Rugby World Cup - Breaking New Boundaries," https://www.bccjapan.com/news/2016/o4/rugby-world-cup-breaking-newboundaries/ (accessed 10 August, 2018).

$5^{2}$ Ibid.

53 British Chamber of Commerce in Japan. 2015. "London 2012 Chief Looks Towards Tokyo 2020," https://www.bccjapan.com/news/2015/o2/lord-deighton/ (accessed 10 August, 2018). 
the LOCOG have offered, publicly, several reassurances to Tokyo demonstrating the sociability of sports diplomacy. ${ }^{54}$ For example, Richard Caborn, the UK's longest ever serving Minister of Sport in the UK (2001-7), who was integral to convincing the Blair government to support London's bid, stated:

I can say to my colleagues in Tokyo, that you are three years out, it must be a bit of a nervous time because you are never quite sure how it is going to go. And I can assure you it was pretty nervous in London and the UK at that time. ${ }^{55}$

Such camaraderie between high profile politicians and members of the organizing committee is evidence of the lines and level of communication cultivated between the London 2012 and Tokyo 2021 preparation experiences.

\section{The Organizing Committee as a Diplomatic Actor beyond the State}

The organizing committee plays a pivotal role in communicating, representing and negotiating the process of organizing an international sport event. It acts in the liminal space between the nation-state and the sporting federation drawing upon different elements of the diplomatic landscape. In the context of the London 2012 Olympic and Paralympic Games, for example, the London Olympic and Paralympic Games Act 2006 supported the organizing committee. The legal act channeled the domestic legal framework into guaranteeing the organizing committee and international federation's rights for the period of preparing and hosting the Games, such as IOC visa and travel regulations for athletes and protection of the Olympic brand. ${ }^{56}$ In historical scholarship, organizing committees have been cited as a source of negotiation; for example, Cha explores the Seoul-Soviet dynamic during the Cold War and the role the "organizing committee undertook... to win Soviet agreement to participate in the 1988 Games." 57 During this period, Cha suggests the organizing committee

54 Nair, D, "Sociability in International Politics: Golf and ASEAN's Cold War Diplomacy." International Political Sociology 14 (2) (2020),196-214; Shimazu, N. "What is Sociability in Diplomacy?" Diplomatica 1 (1) (2019), 56-72.

55 "Sport and Diplomacy: Past Reflections and Looking Toward 2020.

56 Postlethwaite, V., and J. Grix. "Beyond the Acronyms: Sport Diplomacy and the Classification of the International Olympic Committee." Diplomacy and Statecraft, 27 (2) (2016), 295-313.

57 Cha, V. "The Asian Games and Diplomacy in Asia: Korea-China-Russia." International Journal of the History of Sport. 30 (10) (2013), 1176-87, at 1180. 
was a tool of the state. However, with the growth in size and professionalization of international sport events this has seen greater levels of autonomy for the organizing committee.

Logistically the organizing committee comprises an independent workforce of varying size and experience that is time limited to the bidding and hosting process. For example, Girginov and Olsen describe the LOCOG workforce as "defying logic." They note that 15 months before the start of the Games, the organization had 1,162 full-time staff compared to 510 in March 2010; but this number was set to increase to nearly 6,ooo people during the Games. ${ }^{58}$ Beyond the size and scope of the organizing committee, little attention - academic or otherwise - has been paid to the diplomatic role of the organizing committee. Kelly considers the bidding documents and political context of the failed Tokyo 2016 bid and the organizing committee's role in an "internal debate about the wisdom of Tokyo's bid for the 2016 Games, which sharply divided the political leadership and citizen opinion."59 The author illustrates through public dialogue and bidding documents the interplay of political, economic, and ideological interests that shape the direction of bidding and hosting. The bidding committee then into the organizing committee provides a valuable insight into the varying diplomatic roles of national, city-based, and internationally-based actors during a difficult moment of Japanese geopolitical calculations. The calculations, as Kelly frames them, have grown in significance along with the scale of international sport events.

Beyond high-level and public examples of knowledge transfer, there are examples of private channels and entities that enable diplomatic exchanges, many of which are facilitated through the "good offices" of the organizing committee. For example, there is communication between international sport events experts in UK-based universities and organizing committees. The 2018 edition of the Soft Power 30 Report by the consultancy Portland saw the UK's higher education sector as a notable strength: "the UK is home to some of the world's most successful higher education institutions that attract students and academics from across the globe." ${ }^{\prime 60}$ It is evident that this reputation has

$5^{8}$ Girginov, V., and N. Olsen. "Locog: a Temporary Organisation within a High Velocity Environment." In Handbook of the London 2012 Olympic and Paralympic. Volume Two: Celebrating the Games, ed. V. Girginov (Abingdon: Routledge, 2014), 71-83.

59 Kelly, W.W. "East Asian Olympics, Beijing 20o8, and the Globalisation of Sport." International Journal of the History of Sport, 28 (16) (2011), 2261-70, at 2431.

60 https://softpower3o.com/country/united-kingdom/ (accessed 1o February 2019). 
contributed to the knowledge transfer and diplomacy between international sport events and can be quantified by the academic projects around London 2012 that were constructed to enhance knowledge transfer. Examples include Gold and Gold's Olympic Cities: City Agendas, Planning, and the World's Games, 1896-2020 (now in its third edition), with Professor John Gold actively contributing to Tokyo 2021 in his role as Special Appointed Professor in the Graduate School of Governance Studies at Meiji University in Tokyo, Japan. ${ }^{61}$ Other examples show university-to-university knowledge transfer for capitalizing on hosting an event: for example, the University of Birmingham hosted Keio University from Tokyo to discuss and learn about how to host elite athletes. ${ }^{62}$ Such activities have led to greater levels of global collaboration around international sport events, and sports diplomacy themes and opportunities universities can play in this realm.

However, measuring the success and depth of such collaboration and exchange is not a straightforward task, especially when taking into account the different contexts and cultures between the UK and East Asian countries, such as Japan. In remarks about a reciprocal exchange between a large UK-based university, a national UK-based sporting organization and the Tokyo organizing committee in 2018, an interviewee noted it was an "interesting experience of different work cultures, such as, how late into the evening people are willing to work." ${ }^{\prime 3}$ Moreover, reflecting further on their role as an ambassador for the UK:

This visit to Japan was instructive for me personally having not had worked in Japan at all, first of all, viewing first-hand the cultural context and the diversity of the workforce and, therefore, how helpful the advice I was giving was worthwhile... but the advice was not wholly received the same in Japan. A lesson about not trying to export wholesale what the UK experience was. ${ }^{64}$

The reflection demonstrates a different dimension to the discussion as knowledge exchange that is not always seen as positive. This view was also present in

61 Gold, J.R., and M.M. Gold, eds. Olympic Cities: City Agendas, Planning, and the World's Games, 1896-2020 (London: Routledge, 2016).

62 "Olympic Hosts Visit Birmingham for Advice on Welcoming Elite Athletes," 18 November 2016, University of Birmingham. https://www.birmingham.ac.uk/news/latest/2016/11/ Olympic-hosts-visit-Birmingham-for-advice-on-hosting-elite-athletes.aspx (accessed 12 August 2018).

63 Private interview, 2018 (National Sport Organisation Executive, UK).

64 Ibid. 
an interview with a UK-based sport civil servant, who has previously worked in New Zealand. In comparing their experiences, the interviewee stated that in New Zealand colleagues "wanted to know all about England, whilst no one in England has asked [about New Zealand] and have given a very arrogant mindset... two ears one mouth." 65 The reflection here suggests that members of the UK are more than ready to share their experiences, but not necessarily to listen to others. The temptation to attribute this to London's role, in Joseph Conrad's terms, at the "very centre of the Empire on which the sun never sets" is real and speaks to the relationship between sport and empire. ${ }^{66}$

While an important dimension, it has not hampered a proactive UK engagement with the international sport events negotiation process. Hitash Patel, Head of International Sport in the Department for Culture, Media, and Sport in 2017 spoke of the extensive activity between China (People to People Dialogue), India (UK-India Year of Culture), and Japanese partners around "hosting the 2019 Rugby World Cup as well as the 2020 Olympic and Paralympic Games." 67 Brexit, the UK's decision to withdraw from the European Union in June 2016, and its arrival in January 2021, is a prime example of how changing political contexts can shape communications around organizing committees and international sport events. Patel said, "we can't be complacent, and we need to make sure that, despite the perception of the impact of Brexit, we engage positively internationally." 68

Beyond universities, state and non-state sporting bodies, the role of private entities must be drawn upon in the context of organizing committees. The wider international sport events landscape highlights the rise of neoliberalized practices within international sport events preparation, where expertise and knowledge transfer are commodified and bought into organizing committees. UK organizations have particularly flourished post-London 2012 in meeting the market demand. A prime example being a number of the London 2012 organizing committee members starting consultancy firms, such as Doug Arnot, who was the Executive Vice President of LOCOG and is now the Chairman of the Broadstone Group, an international management firm specializing in the planning and delivery of global events. The Broadstone Group has a client list including Sochi 2014 Winter Olympics and Paralympics, Baku 2015 European

65 Private interview, 2018 (Civil Servant Senior Manager, UK).

66 Conrad, J. The Secret Agent: A Simple Tale, and Edition (London: Methuen, 1907) Chapter X.

67 Westminster Media Forum. "Keynote Seminar: Priorities for Integrity and Duty of Care in Sport - Progress, Policy Options and the UK's Global Contribution” (London: Westminster Forum Group, 2017).

Ibid. 
Games, Rio de Janeiro Summer Olympics and Paralympics, Tokyo 2021 Summer Olympics and Paralympics, and the Qatar FIFA Football World Cup. ${ }^{69}$

The approach taken by organizations and individuals to cultivate relations and business during international sport events represents entrepreneurial knowledge exchange and negotiation. This approach was embraced by the UK Foreign and Commonwealth Office (FCO), which stated in the run up to the 2016 Summer Olympics and Paralympics that

- Over 100 experts from the London 2012 games worked closely with Brazilian officials in the four years leading up to the Rio games.

- UK companies won over £650 million in Rio contracts, including planning, design and engineering, ticketing, and hospitality.

- The UK is one of Japan's leading creative partners, and will closely support the Cultural Olympiad in 2021. Close ties between the two nations have been reinforced by recent visits to Japan by the Royal Opera and London Symphony Orchestra in 2015 and the Royal Ballet in 2016. ${ }^{70}$

A 2018 interview with a UK based private sporting consultancy noted that this was not unique to the Olympic movement as private consultants facilitate expertise with many East Asian international sport events. For example, the consultancy had been contracted to assist the International University Sports Federation (FISU) by the organizing committee in Taipei Universiade 2017. The consultancy noted that FISU was very active in having knowledge exchange built into the events the organizing committee through invitations to the 2013 and 2015 editions of FISU. The organizing committee then sought to engage international federations and other key stakeholders in lessons learnt discussion. The model is comparable to the approach taken by the IPC Excellence Program and World Rugby, and offers further insight into how professionalized knowledge exchange is a key practice between organizing committees.

Nonetheless, while the overall trend is toward increasing levels of knowledge exchange across a number of nodes of activity within and across international sport events, there are areas of differentiation between the UK and Japanese organizing committees. In the UK there were three years between

69 "Baku 2015 and the Pop Up Organising Committee," 6 August 2015, https://www.hostcity. com/news/event-management/baku-2015-and-pop-organizing-committee (accessed 14 August, 2018).

$70 \quad$ Foreign and Commonwealth Office. "UK to Share Olympic expertise with Japan," https:// www.gov.uk/government/news/fco-press-release-uk-to-share-olympic-expertise-with-japan (2016) (accessed 28 February 2021). 
London 2012 and the 2015 Rugby World Cup, during which happenstance collaboration was attempted. For example, Debbie Jevans, who was the Director of Sports for London 2012 took over the post of Chief Executive for the England 2015 Rugby World Cup before stepping down from the position during the host preparations. No official public comments were posted to why Jevans resigned, but media coverage speculated:

It was certainly a surprise. Perhaps it wasn't totally unexpected. Rugby has its own heritage, tradition, ethos, moral code and history. It is a club that is not always easy to infiltrate. Debbie Jevans has not had an absolutely smooth ride all the way through. Feathers, since she was appointed in October 2012 after the Olympics to run RWC, have been ruffled. ${ }^{71}$

The disruption and collaboration between the Olympic and Paralympic Games and the "rugby world" in the UK has not been replicated in the Japanese context. In fact, in 2017 the Japanese organizing committees of the Olympic and Paralympic Games, Rugby World Cup, and Kansai World Masters Games in 2021 "entered into a partnership agreement under which the three organizations will exchange knowledge and expertise in order to maximize the benefits and impact of their respective events. ${ }^{72}$ Such a public move was heralded by the IPC as representing "a landmark collaboration agreement" between organizing committees within a nation and region. ${ }^{73}$ The action, unique to the Japanese experience, shows a more substantial unity between the concurrent preparations for international sport events in the country. It shows a progressive approach towards having an international sport events portfolio and synergy between events, something which was not explicitly or publicly present in the UK during the hosting of the Olympic and Paralympic Games and Rugby World Cup.

$71 \quad$ ввс. 2015. "Rugby World Cup: Debbie Jevans Resigns as Boss of 2015 Organisers," https:// www.bbc.co.uk/sport/rugby-union/32091423 (accessed 15 August 2018).

72 "Tokyo 2020 to Join Forces with Rugby World Cup 2019 and World Masters Games 2021 Kansai,"https://tokyo2020.org/en/news/notice/20171120-o1.html (accessed 12 August, 2018).

73 "Tokyo 2020 to team up with Rugby World Cup 2019." https://www.paralympic.org/news/ tokyo-2020-team-rugby-world-cup-2019 (accessed 14 August 2018). 


\section{Conclusions: Global Sporting Transactions in East Asia and Beyond}

A key driver of hosting international sporting events is the effort to change perceptions of the host through the course of the build-up to the event, through its operation, and then with the legacy it leaves for a range of different audiences. Whether a one-off event; the hosting the Summer Olympic Games; or a tournament such as Rugby World Cup of 2015 or 2019 bid documents and preparations enhance the host's reputation in the eyes of the world. The huge amounts of capital that have been required to host premium international sport events in recent decades speak to the investment that is made, not just in monetary terms but also with human and social capital. Bidding organizations and then organizing committees, framed within state-based federations that govern international sport rationalize their investments against benefits and opportunities that hosts believe will flow from the events over the immediate, short, medium, and long term.

By focusing upon the diplomatic processes and actors in Japan- and UK-hosted international sport events, this article complicates a series of dominant voices in understanding sports diplomacy and its application during the past decade. In looking at the organizing committee as an underexplored vector for diplomatic transactions the article has shed light on ways that sport transcends national sovereignties at both sub-state and supra-state levels. In turn this allows for analysis of individuals, and relationships with a plethora of other actions such as sports federations and governing bodies which are party to the knowledge exchange enmeshed in international sport events. This has been explored against three dominant discourses: the Olympic, the Western, and the statist. In each, UK-Japanese examples provide insight into the pre-eminence of the Summer Olympic Games; the propensity for Western understandings of international sport; and the disposition to consider international sport through national lenses. There are manifold reasons for these dominant discourses: the endorsement of the IOC, the Western domination of sporting governance, and the flags, anthems, and kits adorned with national symbols lend themselves such thinking. However, they can all be challenged. The engagement with global sports diplomacy reveals a more complete understanding of the potential for knowledge exchange. In doing so it offers the opportunity for relational engagement with other realms such as cultural diplomacy, cultural relations, and soft power; and with other subfields of research on such topics as grassroots sports exchanges and athlete activism. 